\title{
Histamine and other biogenic amines in food
}

\author{
Agata Durak-Dados $^{\bowtie}$, Mirosław Michalski, Jacek Osek \\ Department of Hygiene and Food of Animal Origin \\ National Veterinary Research Institute, 24-100 Puławy, Poland \\ agatadurak@gmail.com
}

Received: October 10, 2019 Accepted: April 10, 2020

\begin{abstract}
The aim of this paper is to give an overview of the presence of biogenic amines, particularly histamine, in various food products, discuss the most important factors influencing their accumulation, and address potential toxicity and safe limits in food. Biogenic amines are natural components of animal and plant raw materials, where they are present at concentrations appearing non-harmful to human health. Their increased content in foods results from the activity of endogenous enzymes or from the microbial decarboxylation of amino acids during controlled or spontaneous fermentation, processing, storage, and distribution. General knowledge of biogenic amines, factors favouring their formation and their safe limits in food are useful in preventing exposure to their toxic effects on the human body. Based on this information, appropriate prophylaxis can be applied, which will consist primarily of maintenance of good hygiene standards of raw materials and products, employment of appropriate processing procedures and upkeep of sanitary food storage conditions.
\end{abstract}

Keywords: food, biogenic amines, histamine, toxicity.

\section{Characteristics of biogenic amines}

Biogenic amines (BAs) are basic nitrogenous compounds with a diverse structure found in many types of food, such as fish and fishery products, meat and meat products, cheeses, wine, beer, and other fermented foods and drinks (33). They can arise due to the decarboxylation of amino acids and the amination or transamination of ketones and aldehydes with the coaction of bacterial microorganisms (57). At the cellular level, BAs have an impact on the synthesis of proteins, hormones, and alkaloids. BAs also affect DNA replication and cell membrane permeability. In addition, they are involved in the regulation of body temperature, blood pressure, and brain activity (9). On the one hand, BAs are necessary to maintain cell viability and the proper course of many metabolic processes, but on the other, they can also have toxic or carcinogenic effects as precursors of carcinogenic $\mathrm{N}$-nitro compounds (38).

In terms of chemical structure, BAs are divided into three groups: aliphatic (e.g. spermidine, spermine, cadaverine, or putrescine), aromatic (e.g. phenylethylamine or tyramine), and heterocyclic (e.g. tryptamine or histamine)
(57). Aliphatic amines are components of all living cells, in which they play many biochemical and physiological roles. They can originate from endogenous biosynthesis carried out by microorganisms present in the intestines or can be introduced into the body with food (70). Aromatic amines belong to the class of neurotransmitters called catecholamines, which are defined by the presence of the catechol ring and the amine side chain (7). For example, dopamine is an important neurotransmitter in the autonomic nervous system. It is an autocrine/paracrine substance that is produced in the kidneys (26). Tyramine, which is also a catecholamine, is a tissue hormone (17). Heterocyclic amines, e.g. histamine, are found in large quantities in the gastrointestinal mucosa, muscle, skin, liver, lung, and leukocytes (61). Fig. 1 shows the chemical structures of selected biologically active BAs.

The toxicity of small doses of BAs is negligible, but the consumption of a large amount of foods rich in these amines may cause serious health effects. Low doses of BAs are quickly metabolised in the digestive tract to less bioactive products. The enzymes involved in the detoxification of amines in the body are monoamine oxidase (MAO), diamine oxidase, and 
polyamine oxidase (49). Exogenous amines absorbed from food are rapidly degraded by these oxidases, but in allergic people taking inhibitors of these enzymes or after the consumption of very large amounts of amines, the neutralisation process is inhibited or slowed, resulting in the accumulation of amines in the body (63). Therefore, contamination with any biogenic amines can lead to food poisoning and even to development of other symptoms such as allergies (24). Histamine, putrescine, and tyramine are the BAs responsible for the most serious and common poisoning (57). The final toxic effect depends on many factors, such as the dose of histamine, presence of other amines, activity of aminooxidases, or the individual's intestinal physiology (6). Symptoms of histamine poisoning are urticaria, a fall in blood pressure, tachycardia, nausea, vomiting, diarrhoea, headache, and convulsions, and they occur within a few hours of food intake. Excessive consumption of tyramine is followed by headache, palpitations, nausea and vomiting, a rise in blood pressure, sweating, and stiffness in the neck (18). The physiological effects of other BAs are very diverse (6).

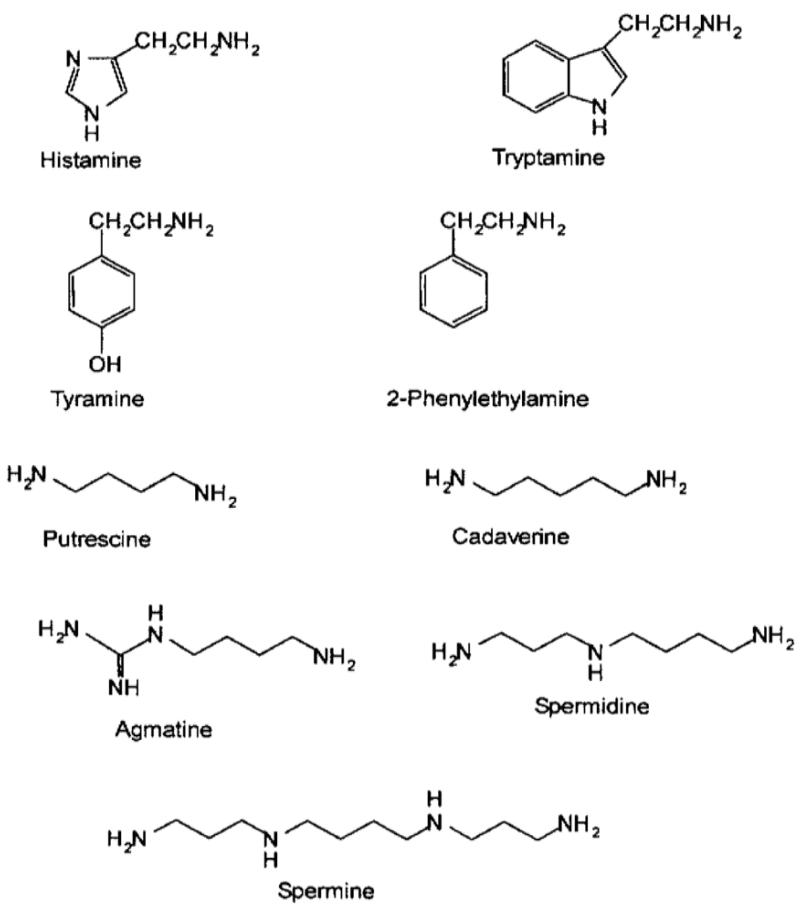

Fig. 1. Chemical structures of selected biogenic amines (50)

\section{Biogenic amines in food}

Biogenic amines can be found in any group of protein-containing foods. BAs are indicators of the freshness and suitability for consumption of certain foods, e.g. fish, and in certain cases improve food's organoleptic characteristics, e.g. in ripening cheese (19, $58,59)$. The level of BAs is also a marker of the hygienic quality of food, indicating, when high, noncompliance with hygiene requirements during the processing of raw materials and the presence of numerous undesirable bacteria (2). In non-fermented food, the presence of BAs above a certain naturally occurring level is considered a sign of possible microbiological contamination. In fermented vegetable products, some amounts of BAs, especially putrescine, were found in sauerkraut juice, pickled vegetables (kimchee), and fermented soybeans $(14,51)$. A paste product, miso, which is formed by fermenting cereal and soybean seeds with the coaction of mould, yeast and bacteria, has been found to contain tyramine and histamine (35). High levels of biogenic amines may also occur in tomatoes and bananas (tyramine, tryptamine), plums (tyramine), spinach (histamine), and legumes (31).

\section{Fish and fish products}

Fish and fish products show the highest levels of BAs. This applies mainly to fish species containing significant amounts of free histidine, which can be transformed into histamine under appropriate conditions (60). In mackerel, herring, tuna, and sardines other amines have been detected in addition to histamine including putrescine, cadaverine, tyramine, spermine, and spermidine (57). The content of histamine, putrescine and cadaverine usually increases during the spoilage of fish, while the levels of spermine and spermidine decrease at that time (51). The most common type of cases of amine food poisoning associated with fish consumption were connected with mackerel. The formation of histamine in mackerel and other marine fish containing large amounts of endogenous histidine is more related to the activity of microflora than to the activity of decarboxylase naturally occurring in fish (18). The increase in histamine level in fish can be very rapid, which indicates the intensive growth of microorganisms. The main bacterial species that are responsible for the toxicity of fish are Proteus morganii, Hafnia alvei, Aeromonas hydrophila, Vibrio alginolyticus, Pseudomonas, and Klebsiella. The enzymes produced by these bacteria can cause formation of histamine doses dangerous for human health in a very short time when growth conditions are favourable, e.g. when storing fish at elevated temperatures. Low temperature storage is the most common method for preventing the growth of bacteria involved in the production of histamine (39). This amine is rarely produced when the raw material contains salt, which has an inhibitory effect on histidine decarboxylase activity (60). In studies on highly salted herrings, no microbiological changes or increases in amine content were observed. However, bacteria that are resistant to high salt levels can produce more biogenic amines, which was seen in sardines, in which amines were detected even at $12 \%$ 
salinity. Furthermore, the histamine content also increased during the period through which fish were preserved by pickling and storing appropriately. The content of BAs is not significantly reduced by sterilisation, as up to $90 \%$ of the amines were found to remain (15). In the case of canned fish, the content of histamine depends on many factors, including freshness of the raw material, species of fish, and transport conditions (57).

\section{Milk and cheeses}

A detectable amount of histamine can be found in raw milk, and its level increases during processing. In pasteurised milk, histamine occurs in the range of 0.3-0.7 ppm and in UHT milk, up to $0.8 \mathrm{ppm}$, while in fermented dairy products it constitutes a tenfold larger proportion (11). Cheeses are the next most common food products associated with poisoning caused by histamine after fish and fish products (22). In some types of cheeses, the level of biogenic amines during maturation is high at the beginning of the process and then decreases. This change can be exploited to assess the degree of maturity of these products (52). Many amines, such as histamine, tyramine, cadaverine, putrescine, tryptamine, and phenylethylamine, have been detected in various ripening cheeses (22). The amounts of BAs in cheeses ranged from undetectable levels up to $2,500 \mathrm{mg} / \mathrm{kg}$ (histamine), 2,210 mg/kg (tyramine), $300 \mathrm{mg} / \mathrm{kg}$ (tryptamine), 1,390 mg/kg (cadaverine), and $684 \mathrm{mg} / \mathrm{kg}$ (putrescine). In sheep cheeses, histamine, cadaverine, tyramine, and putrescine were also detected although at lower levels $(13-52 \mathrm{mg} / \mathrm{kg})(23)$. In brie and camembert cheeses high concentrations of cadaverine, putrescine, and tyramine were recorded, with more amines found in the rind than in the cheese. However, in most of the tested cheeses, less than $10 \mathrm{mg}$ of biogenic amine was identified in $1 \mathrm{~kg}(45)$.

\section{Meat and meat products}

The high content of protein and free amino acids determines that meat and meat products are favourable environments for the growth of bacteria producing biogenic amines (13). The naturally occurring compounds in fresh meat are the polyamines spermine and spermidine. The spermine content is between 20 and $60 \mathrm{mg} / \mathrm{kg}$ and the level of spermidine rarely exceeds $10 \mathrm{mg} / \mathrm{kg}$ (33). In meat during storage, the level of histamine, cadaverine, putrescine, and tyramine increases, the spermine content decreases slightly, and the spermidine concentration remains unchanged (33, 55). The relationship between the content of biogenic amines in food products and the storage time of those products can be used to monitor food spoilage (68). An increase in the level of biogenic amines caused by microorganisms is considered as an indicator of the poor quality of the products which contain them, especially when they are non-fermented products (9). The biogenic amines index (BAI), which is the sum of histamine, cadaverine, putrescine, and tyramine, can be used as a freshness marker for meat products. The BAI value for fresh meat should not exceed $5 \mathrm{mg} / \mathrm{kg}$, BAI between 20 and $50 \mathrm{mg} / \mathrm{kg}$ indicates poor meat quality, and a value above $50 \mathrm{mg} / \mathrm{kg}$ conveys that its quality is very poor (33). However, the BAI is mainly useful for fresh meat and heat-treated products, and there is no BAI criterion for assessing the quality of raw-ripening meat products (55). One of the most important biochemical changes occurring during the ageing of dry-cured fermented meat products is protein proteolysis, which results in the generation of large peptides, which are then degraded to oligopeptides and free amino acids (FAAs) $(34,44)$. In addition to FAAs' biological value, they directly contribute to the taste of dry fermented meat products and the development of their typical aroma because they are precursors of many volatile compounds (3). Proteolysis is favoured by the denaturation of proteins as a consequence of acidity increase, dehydration, and the action of sodium chloride (21). The non-protein nitrogen fraction that includes the presence of free amino acid precursors of BAs increases during sausage fermentation and drying. The production of BAs in dry sausages has often been related to the proteolytic activity of microorganisms present in the meat during fermentation and ripening, which yields higher amounts of biogenic amine precursors (31).

\section{Microorganisms as producers of amino acid decarboxylases}

The ability to produce amino acid decarboxylases is not common among microorganisms, but most bacterial strains used in food technology have the ability to form BAs. Enterobacteriaceae isolated from sausages are generally considered microorganisms with high decarboxylase activity, particularly in relation to the production of cadaverine and putrescine. However, in the studies of Halász et al. (31), it was shown that many Enterobacteriaceae, particularly E. cloacae and E. aerogenes, can also produce considerable levels of histamine. Other microorganisms like Klebsiella oxytoca (53), Escherichia coli (62), and Proteus morganii (13) were also reported as amino acid decarboxylase producers. Ground beef contaminated with Proteus morganii contained $595 \mu \mathrm{g}$ of histamine in $1 \mathrm{~g}$, while the level of this amine in Proteus-free meat was about $8 \mu \mathrm{g} / \mathrm{g}$ (67). Amine-producing lactic acid bacteria such as Lactobacillus brevis, L. buchneri, L. curvatus, L. carnis, L. divergens, and L. hilgardii have been isolated from meat and meat products (47). In salami, histamine production has been associated with the presence of the Gram-negative bacteria 
Pseudomonas fluorescens, Citrobacter freundii, and Acinetobacter calcoaceticus and Gram-positive microorganisms including micrococci and staphylococci (57). However, it should be emphasised that not all strains of the same bacterial species have the ability to produce BAs (20). Microorganisms capable of amino acid decarboxylase production can constitute natural microflora of food raw materials, penetrate into food during production or storage, or be intentionally introduced as starter cultures in the production of fermented food (39). High content of putrescine indicates an increased number of microorganisms and thus inferior freshness of the meat containing it. The content of BAs varies in fermented products due to products' different microbiological profiles. The method of food preparation has a great impact on the microflora, which is associated with multiple interactions between the ingredients (17). In Italian sausages, the presence of BAs is closely related to the composition of the microflora in these products. In various Spanish meat products, higher concentrations of tyramine were found in the finished product than in the raw material (56).

\section{Factors affecting the formation of biogenic amines in food}

In addition to the presence of specific bacterial strains and the quality of the raw material, there are many factors that affect BA formation: temperature, $\mathrm{pH}$, availability of substrates (amino acids), water activity $\left(\mathrm{A}_{\mathrm{w}}\right), \mathrm{NaCl}$ content, and redox potential (29, 40, 43).

\section{Temperature}

The influence of temperature on the formation of biogenic amines in food has been described. Several authors have shown that the content of BAs increases at higher temperature and as storage time extends (29, 31, 39). Although no effect of temperature was demonstrated on the amount of tyramine formed in anchovies (56), it has been shown that low storage temperature is not sufficient to inhibit the formation of biogenic amines, e.g. histamine, in sardines (1). During storage, the concentrations of putrescine and cadaverine in pork increase at $5^{\circ} \mathrm{C}$ and $20^{\circ} \mathrm{C}$, while the levels of spermidine and spermine decrease (31). Maijala et al. (47) showed that the effect of temperature on the formation of biogenic amines depends on the type of starter culture used. Higher fermentation temperature $\left(24^{\circ} \mathrm{C}\right)$, optimal for the growth of starter cultures, inhibits the growth of microorganisms responsible for the production of BAs. Therefore, when choosing a starter culture, it is necessary to take into account not only the need for the presence of bacteria that do not produce decarboxylating enzymes, but also whether they have the ability to grow under the temperature conditions provided for the process.

\section{pH}

Acidity (pH) is also a very important factor influencing the formation of amines, because the activity of amino acid decarboxylases is higher in acidic conditions, i.e. at $\mathrm{pH} 4.0-5.5$ (67). The conversion of histidine to histamine by Klebsiella pneumoniae isolated from tuna was mostly active at $\mathrm{pH}$ approximately 4.0 , and at $\mathrm{pH}$ in the region of 6.0 the activity dropped to $70 \%$ (5). Higher amounts of histamine were also found in mackerel with lower $\mathrm{pH}$ (56). The optimum acidity of cheeses for the formation of tyramine is $\mathrm{pH} 5.0$ (22). In the case of meat products, the addition to sausages of glucono-deltalactone, which reduces $\mathrm{pH}$, and consequent reduction of the number of Enterococci and coliform bacteria resulted in weaker histamine and putrescine formation (46). Bover-Cid et al. (13) pointed out that a rapid and sharp decrease in $\mathrm{pH}$ in sausages inhibits the growth of the amine-positive microorganisms, particularly Enterobacteriaceae, and protects the meat product from biogenic amine formation. Power of hydrogen is a key factor in the control of biogenic amine formation in fermented meat products because it affects microbiological safety and amino acid decarboxylase activity.

\section{Water activity $\left(\mathrm{A}_{\mathrm{w}}\right)$ and $\mathrm{NaCl}$ content}

The variation in the water content and in the salt: water ratio during fermentation and storage of fermented sausages has an important impact on microbial growth. The rate of amines production by L. delbrueckii subsp. Bulgaricus was considerably reduced when salt concentration in the medium increased from $0 \%$ to $6 \%$ (16). Henry Chin and Koehler (32) demonstrated that $\mathrm{NaCl}$ concentrations ranging from $3.5 \%$ to $5.5 \%$ inhibit histamine production. This influence can be attributed to reduced cell yields obtained in the presence of high $\mathrm{NaCl}$ concentrations and to damage of the bacterial cell membrane by decarboxylase enzymes (64). Chemicals used in the production of raw maturing meat products have a significant influence on the formation of biogenic amines. The inhibitory effect of $\mathrm{NaCl}$ on the formation of biogenic amines has been demonstrated in studies conducted by Gardini et al. (29) on the interaction between $\mathrm{pH}$, temperature, and $\mathrm{NaCl}$ concentration (from $2 \%$, to $6 \%$ ) on the formation of biogenic amines. $\mathrm{NaCl}$ concentration effectively suppressed the amine production in the medium after $72 \mathrm{~h}$ of incubation (64). Gardini et al. (29) stated that a $5 \% \mathrm{NaCl}$ concentration minimises the presence of the amines, and Sumner et al. (64) and Joosten (36) 
obtained similar results. Roseiro et al. (54) studied the effects of final $\mathrm{NaCl}$ concentrations in dry fermented pork sausage on biogenic amine levels and reported that $6 \%$ salt content reduced the total biogenic amine levels more significantly than $3 \%$. Variations in microflora composition and differences in biogenic amine formation could be attributed to different salt contents (12). Santos (57) showed that histamine production is inhibited by the addition of salt to mackerel stored at $25^{\circ} \mathrm{C}$ and that the inhibitory effect was proportional to the increase in salt concentration in the fish brine. The ripening period had a significant effect on the water activity $\left(A_{w}\right)$ of fermented meat (30, 37) exemplified by the $A_{w}$ values of fermented beef aged for 2 months being significantly lower than those for fermented beef aged for 21 days. Water activity decreased gradually during ageing, with a mean value of 0.936 for samples aged for 2 months and 0.906 for samples aged for 36 months. The decrease in water activity in fermented meat results from a progressive protein proteolysis leading to the production of free amino acids (69).

\section{Redox potential}

Another factor affecting the content of biogenic amines in raw maturing products is the oxidoreductive potential. Its effect on the activity of bacterial decarboxylases is ambiguous. Under anaerobic conditions, Enterobacter cloacae produces half as much putrescine as it does under aerobic conditions. The synthesis of cadaverine by Klebsiella pneumoniae under anaerobic conditions is significantly reduced, although this microorganism acquires the ability to synthesise putrescine. On the other hand, it has been shown that lowering the oxidoreductive potential stimulates the production of histamine. In the presence of oxygen, notably less activity of histidine decarboxylase is possible $(31,39)$.

\section{Toxicity of biogenic amines}

BAs are determined in food either as food quality markers or for their potential toxicity. Despite the many important roles that biogenic amines play in the human body, consumption of food containing high levels of BAs may lead to various food-borne diseases. Histamine and 2-phenylethylamine may affect the nervous system. The effects of tyramine and tryptamine are similar vascular causing hypertension, headache, fever, and sometimes vomiting and sweating. The presence of tyramine in food is also very important due to its toxicity and potential interreaction with the MAO inhibitors that raise blood pressure (60). Most poisoning cases caused by tyramine are associated with cheeses, but cases are also ascribed to other foods such as pickled herring, meat products, avocados, soy sauce, miso, chicken, beef liver, and caviar. Putrescine and cadaverine together with tyramine and histamine present in food have been responsible for toxic effects in humans (10). Furthermore, simultaneous occurrence of nitrates (III) and acids in food, together with cadaverine, putrescine, spermine, and spermidine may lead to the production of carcinogenic nitrosamines (25). When processing fatty products (e.g. bacon) at high temperatures in the presence of water, putrescine, spermidine, and $\mathrm{N}$-nitrosopiperidine may be formed (6).

It has been shown that histamine is the most toxic amine found in food. The most common intoxications known as "histamine poisoning" or scombroid (intoxication from fish) involve a variety of symptoms: reddening of the skin, oedemas and rashes, and dilatation of peripheral blood vessels resulting in hypotension, headache, diarrhoea, and vomiting (50). High histamine accumulation can also lead to respiratory failure, sweating, palpitations, rash, and a burning sensation (6). The body's intolerance to histamine also causes nasal congestion, asthmatic breathing, arrhythmia, urticaria, pruritus, and even dysmenorrhea (48). When present, secondary amines including putrescine and cadaverine have a synergistic effect and make the histamine toxicity in food poisoning more potent (66). Other authors $(27,33,63)$ confirmed that histamine alone may not cause intoxication at a low level, but putrescine and cadaverine at five times higher concentrations than histamine strengthen its toxicity through the inhibition of histamine-oxidising enzymes. However, the final outcome of its toxic effects on the body depends on many factors, such as the dose of histamine, the presence of other amines, the activity of aminooxidases, and the individual physiology of the intestines (6). The kidneys have a considerable capacity for removing histamine from blood. When healthy individuals were infused intravenously with histamine, a large proportion of the amine was methylated by the kidneys and excreted in urine. A smaller proportion was eliminated in urine unchanged (8). The treatment for histamine toxicity involves the use of histamine receptor antagonists but occasionally, salbutamol and adrenalin may also be applied (4). As mentioned above, the doses of histamine which cause allergic reactions are different and vary between individuals, and a dose of 5-10 mg may cause a reaction in sensitive people. It is assumed that it should not exceed $200 \mathrm{mg} / \mathrm{kg}$ (18). Intakes of $100-800 \mathrm{mg} / \mathrm{kg}$ for tyramine and $30 \mathrm{mg} / \mathrm{kg}$ for phenylethylamine are considered toxic, although as little as $3 \mathrm{mg}$ of phenylethylamine causes migraine headaches in sensitive individuals, while $6 \mathrm{mg}$ of tyramine is considered a dangerous dose for those taking MAO inhibitors (57). Other biogenic amines such as putrescine or cadaverine are not toxic, but may affect histamine and thus increase its negative effect on humans (42). 
Maintaining checks on biogenic amine formation is mainly focused on the monitoring of the growth of biogenic amine-forming bacteria. It is because the histamine is heat stable $(14,41,57)$ and is not detectable organoleptically (65). Once produced, histamine is difficult to destroy by freezing, cooking, pasteurisation, sterilisation, or smoking (28). Therefore, the quality of the raw material is the most important factor affecting the content of biogenic amines in raw maturing products (12).

\section{Conclusion}

The demand for safer foods has promoted more research into biogenic amines over the past decades, because better understanding of the mechanisms by which microorganisms create BAs in food is necessary to prevent their formation. BAs are present in many different foods and beverages and their concentrations vary widely between and within food types. The presence of biogenic amines in food products can be controlled by good hygienic practice both at the stage of receiving raw material and during its processing. A method for controlling BAs in food is refrigeration. However, some bacteria that form biogenic amines can grow below $5^{\circ} \mathrm{C}$, thus refrigeration alone is not always sufficient. Emerging control measures for delaying biogenic amine formation need to be considered, such as irradiation, packaging, high hydrostatic pressure, microbial modelling, and the use of food additives or preservatives. These methods delay BA formation in food primarily through the inhibition of bacteria growth or decarboxylase enzyme activity responsible for amines production. In fermented foods, shortening the fermentation stage by the use of carefully selected bacterial strains and thereby preventing the development of undesirable microorganisms can be helpful in reducing the formation of toxic amines. The toxicological significance of biogenic amines has been the subject of many studies, which clearly show that histamine, tyramine, tryptamine, cadaverine, and ethylamine are the cause of food intoxication, especially in sensitive people. Therefore, even though data on BAs is currently not included in food composition lists, information on their existence, distribution, and concentration in fermented foods is crucial and may be useful for the food industry, health professionals, and consumers. Knowledge of the products in which biogenic amines are most common, as well as the factors favouring their formation, can help to prevent poisoning resulting from excessive BAs accumulation in food.

Conflict of Interests Statement: The authors declare that there is no conflict of interests regarding the publication of this article.
Financial Disclosure Statement: This study was supported by the Polish Ministry of Science and Higher Education within the statutory activity of the Institute.

Animal Rights Statement: None required.

\section{References}

1. Abouch L., Afilal M., Benabdeljelil H.: Quantitative changes in bacteria, amino acids and biogenic amines in sardine (Sardina pilchardus s) stored at ambient temperature $\left(25-28^{\circ} \mathrm{C}\right)$ and in ice. Int J Food Sci Technol 1991, 26, 297-306.

2. Alberto M., Arena M., Manca de Nadra M.C.: A comparative survey of two analytical methods for identification and quantification of biogenic amines. Food Control 2002, 13, 125-129.

3. Aro Aro J.M., Nyam-Osor P., Tsuji K., Shimada K., Fukushima M., Sekikawa M.: The effect of starter cultures on proteolytic changes and amino acid content in fermented sausages. Food Chem 2010, 119, 279-285.

4. Attaran R.R., Probst F.: Histamine fish poisoning: a common but frequently misdiagnosed condition. J Emerg Med 2002, 19, 474-475.

5. Baranowski J., Brust P., Frank H.: Growth of Klebsiella pneumoniae $\mathrm{UH}-2$ and properties of its histidine decarboxylase system in resting cells. J Food Biochem 1985, 9, 349-360.

6. Bardocz S.: Polyamines in food and their consequences for food quality and human health. Trends Food Sci Tech 1995, 6, 341-346.

7. Ben-Jonathan N., Hnasko R.: Dopamine as a prolactin (PRL) inhibitor. Endocr Rev 2001, 22, 724-727.

8. Bentley S., Bottarelli A., Bonardi S.: Detoxification and involves S - adenosylmethionine as donor of methyl. Ing Alimen 1995, 5, 32-35.

9. Berthold A., Nowosielska D.: Biogenic amines in food. Med Weter 2008, 64, 745-748.

10. Bjeldanes L.F., Schutz D.E., Morris M.M.: On the aetiology of scombroid poisoning: Cadaverine potentiation histamine toxicity in the guinea pig. Food Cosmet Toxicol 1978, 16, 157-159.

11. Bodmer S., Imark C., Kneubühl M.: Biogenic amines in foods: Histamine and food processing. Inflamm Res 1999, 48, 296-300.

12. Bover-Cid S., Hugas M., Izquierdo-Pulido M., VidalCarou M.C.: Amino acid-decarboxylase activity of bacteria isolated from fermented pork sausages. Int J Food Microbiol 2001, 66, 185-189.

13. Bover-Cid S., Miguelez-Arrizado M.J., Latorre Moratalla L.L., Vidal Carou M.C.: Freezing of meat raw materials affects tyramine and diamine accumulation in spontaneously fermented sausages. Meat Sci 2006, 72, 62-68.

14. Brink B., Damink C., Joosten H., Huis in 't Veld J.: Occurrence and formation of biologically active amines in foods. Int $\mathrm{J}$ Food Microbiol 1990, 11, 73-84.

15. Broczek M., Rautenstrauch D., Windyga B., Ścieżyńska H., Jędra M., Badowski P., Karłowska B.: The content of histamine and tyramine depending on the microbiological quality of salted herrings, stored at different temperatures. Roczn PZH 2003, 54, $87-95$.

16. Chander H., Batish V.H., Babu S., Singh R.S.: Factors affecting amine production by a selected strain of Lactobacillus bulgaricus. J Food Sci 1989, 54, 940-942.

17. Cieślik I., Migdał W.: Aminy biogenne w żywności. Bromatol Chem Toksykol 2011, 4, 1087-1096.

18. Czerniejewska-Surma B.: The influence of selected factors of biological and technological processes for histamine content in foodstuffs. Agricultural University in Szczecin, Szczecin 2006, p. 92.

19. Dąbrowski T., Stodolnik L.: Changes of histidine and histamine in the muscle tissue of the cable (Tinca tinca L.) and bream 
(Abramis gate L.) during storage in ice. Med Weter 1966, 22, 32-40.

20. Deepika Priyadarshani W.M., Rakshit S.K.: Screening selected strains of probiotic lactic acid bacteria for their ability to produce biogenic amines (histamine and tyramine). Int J Food Sci Tech 2011, 46, 2062-2069.

21. DeKetelaere A., Demeyer D.I., Vanderkerhove P., Verveake L.: Stoichiometry of carbohydrate fermentation during dry sausage ripening. J Food Sci 1974, 39, 297-300.

22. Diaz-Cinco M., Fraijo G., Grajewa P., Lozano-Taylor J., de Mejia E.: Microbial and chemical analysis of Chihuahua cheese and relationship to histamine. J Food Sci 1992, 57, 355-356.

23. Dicáková Z., Dudriková E., Cabadaj R.: Biogenic amines in ewe's milk lump cheese and bryndza. Bull Vet Inst Puławy 2004, 48, 53-57.

24. Diel E., Bayas N., Müller S., Bott A., Schimpf D., Diel F.: Histamine containing food: establishment of a German food intolerance databank (NFID). Inflamm Res 1997, 46, Supplement 1, 87-88.

25. Eerola S., Sagues A.X.R., Lilleberg L., Aalto H.: Biogenic amines in dry sausages during shelf-life storage. Eur Food Res Technol 1997, 205, 351-355.

26. Eldrup E.: Significance and origin of DOPA, DOPAC, and dopamine-sulphate in plasma, tissues, and cerebrospinal fluid. Dan Med Bull 2004, 51, 34-36.

27. Emborg J., Dalgaard P.: Formation of histamine and biogenic amines in cold-smoked tuna: an investigation of psychrotolerant bacteria from samples implicated in cases of histamine fish poisoning. J Food Prot 2006, 69, 897-906.

28. Etkind P., Wilson M.E., Gallagher K., Cournoyer J.: Bluefishassociated scombroid poisoning. J Am Med Assoc 1987, 258, 3409-3410.

29. Gardini F., Martuscelli M., Caruso M.C., Galgano F., Crudele M.A., Favati F., Guerzoni M.E., Suazi G.: Effects of pH, temperature and $\mathrm{NaCl}$ concentration on the growth kinetics, proteolytic activity, and biogenic amine production of Enterococcus faecalis. Int J Food Microbiol 2001, 64, 105-117.

30. Gök V., Obuz E., Akkaya L.: Effects of packaging method and storage time on the chemical, microbiological, and sensory properties of Turkish pastirma - a dry cured beef product. Meat Sci 2008, 80, 335-344

31. Halász A., Baráth Á., Simon-Sarkadi L., Holzapfel W.: Biogenic amines and their production by microorganisms in food. Food Sci Technol 1994, 5, 42-48.

32. Henry Chin K.D., Koehler P.E.: Effects of salt concentration and incubation temperature on formation of histamine, phenethylamine, tryptamine and tyramine during miso fermentation. J Food Prot 1986, 49, 423-427.

33. Hernández-Jover T., Izquierdo-Pulido M., Veciana-Nogues M.T., Marine-Font A., Vidal-Carou M.C.: Biogenic amine and polyamine contents in meat and meat products. J Agric Ford Chem 1997, 45, 2098-2102.

34. Hughes M.C., Kerry J.P., Arendt E.K., Kenneally P.M., McSweeney P.L.H., O'Neill E.E.: Characterization of proteolysis during the ripening of semi-dry fermented sausages. Meat Sci 2002, 62, 205-216.

35. Ibe A., Nishima T., Kasai N.: Bacteriological properties of and amine-production conditions for tyramine-and histamineproducing bacterial strains isolated from soybean paste (miso) starting materials. Japan J Toxicol Environ Health 1992, 38, 403-409.

36. Joosten H.M.L.J.: Conditions allowing the formation of biogenic amine in cheese. 4. Factors influencing the amounts formed. Neth Milk Dairy J 1988, 41, 329-357.

37. Kaban G.: Sucuk and pastirma: Microbiological changes and formation. Meat Sci 2013, 95, 912-918.

38. Kączkowski J.: Podstawy biochemii. WNT, Warszawa 2002, pp. 362-364.

39. Karovičová J., Kohajdová Z.: Biogenic amines in food. Chem Pap 2005, 59, 70-79.
40. Komprda T., Smělá D., Pechová P., Kalhotka L., Štencl J., Klejdus B.: Effect of starter culture, spice mix and storage time and temperature on biogenic amine content of dry fermented sausages. Meat Sci 2004, 67, 607-616.

41. Kurt S., Zorba O.: The effects of ripening period, nitrite level and heat treatment on biogenic amine formation of "sucuk" A Turkish dry fermented sausage. Meat Sci 2009, 82, 179-184.

42. Landete J., Rivas B., Macrobal A., Munoz R.: Molecular methods for the detection of biogenic amine-producing bacteria on foods. Int J Food Microbiol 2007, 117, 258-269.

43. Latorre-Moratalla M.L., Veciana-Nogués T., Bover-Cid S., Garriga M., Aymerich T., Zanardi E., Ianieri A., Fraqueza M.J., Patarata L., Drosinos E.H., Lauková A., Talon R., VidalCarou M.C.: Biogenic amines in traditional fermented sausages produced in selected European countries. Food Chem 2008, 107, 912-921.

44. Lorenzo J.-M., García Fontán M.-C., Franco I., Carballo J.: Proteolytic and lipolytic modifications during the manufacture of dry-cured lacón, a Spanish traditional meat product: effect of some additives. Food Chem 2008, 110, 137-149.

45. Maijala R., Eerola S.: Biogenic amines, In: Encyclopedia of Dairy Science, edited by H. Roginski, J.W. Fluguay, P.F.Fox. Academic Press, Amsterdam 2002, pp. 156-162.

46. Maijala R., Eerola S., Aho M., Hirn J.: The effect of GDLinduced $\mathrm{pH}$ decrease on the formation of biogenic amines in meat. J Food Prot 1993, 50, 125-129.

47. Maijala R., Nurmi E., Fischer A.: Influence of processing temperature on the formation of biogenic amines in dry sausages. Meat Sci 1995, 39, 9-22.

48. Maintz L., Schwarzer V., Bieber T., Van der Ven K., Novak N.: Effects of histamine and diamine oxidase activities on pregnancy: a critical review. Hum Reprod Update 2008, 14, 485-495.

49. McCabe-Sellers B.J., Staggs C.G., Bogle M.L.: Tyramine in foods and monoamine oxidase inhibitor drugs: a crossroad where medicine, nutrition, pharmacy, and food industry converge. J Food Compos Anal 2006, 19 (suppl), 58-65.

50. Onal A.: A review: current analytical methods for the determination of biogenic amines in foods. Food Chem 2007, 103, 1475-1486.

51. Pinho O., Ferreira I., Mendes E., Oliveira B., Ferreira M.: Effect of temperature on evolution of free amino acid and biogenic amine contents during storage of Azeitao cheese. Food Chem 2001, 75, 287-291.

52. Rak L.: Biogenic amines in cheeses. Med Weter 2005, 61, 391-393.

53. Roig-Sagues A.X., Hernandez-Herrero M., Lopez-Sabater E.I., Rodriguez-Jerez J.J., Mora-Ventura M.T.: Histidine decarboxylase activity of bacteria isolated from raw and ripened Salsichon, a Spanish cured sausage. J Food Prot 1996, 59, 516-520.

54. Roseiro C., Santos C., Sol M., Silva L., Fernandes I.: Prevalence of biogenic amines during ripening of a traditional dry fermented pork sausage and its relation to the amount of sodium chloride added. Meat Sci 2006, 74, 557-563.

55. Ruiz-Capillas C., Jiménez-Colmenero F.: Biogenic amines in meat and meat products. Crit Rev Food Sci 2004, 44, 489-499.

56. Santos C., Pena M., Rivas J.: Changes in tyramine during chorizo-sausage ripening. J Food Sci 1986, 51, 518-519.

57. Santos S.: Biogenic amines: their importance in foods. Int J Food Microbiol 1996, 29, 213-231.

58. Scheibner G.: The importance of biogenic amines in food hygiene. Med Weter 1991, 47, 496-450.

59. Schneller R., Good P., Jenny M.: Influence of pasteurized milk, raw milk, and different ripening cultures on biogenic amine concentrations in semi-soft cheeses during ripening. Zeit Lebensm Unters Forsch A 1997, 204, 265-272.

60. Shalaby A.R.: Survey on biogenic amines in Egyptian foods: sausage. J Sci Food Agric 1993, 62, 291-293. 
61. Sieja K.: Peripheral biogenic monoamines and hormonal profile in women with fibrotic cystic lesions of the mammary gland. Ann Acad Med Stet 2001, 68, 17-21.

62. Silla Santos, M.H.: Amino acid decarboxylase capability of microorganisms isolated in Spanish fermented meat products. Int J Food Microbiol 1998, 39, 227-230.

63. Stratton J.E., Hutkins R.W., Taylor S.L.: Biogenic amines in cheese and other fermented foods: a review. J Food Prot 1991, $54,460-470$

64. Sumner S.S., Speckhard H.W., Somers E.B., Taylor S.L.: Factors controlling histamine production in Swiss cheese inoculated with Lactobacillus buchneri. J Dairy Sci 1990, 73, 3050-3058.

65. Tapingkae W., Tanasupawat S., Parkin K.L., Benjakul S., Visessanguan W.: Degradation of histamine by extremely halophilic archaea isolated from high salt-fermented fishery products. Enzyme Microb Technol 2010, 46, 92-99.
66. Taylor S.L., Speckhard M.W.: Isolation of histamine-producing bacteria from frozen tuna. Mar Fish Rev 1983, 45, 35-39.

67. Teodorovic V., Buncic S., Smiljanic D.: A study of factors influencing histamine production in meat. Fleischwirtschaft 1994, 74, 170-172.

68. Vinci G., Antonelli M.: Biogenic amines: quality index of freshness in red and white meat. Food Control 2002, 13, 519-524.

69. Wójciak K.M., Solska E.: Evolution of free amino acids, biogenic amines and $N$-nitrosoamines throughout ageing in organic fermented beef. Acta Sci Pol Technol Aliment 2016, 15, 191-200.

70. Zoumas-Morse C., Rock C.L., Quintana E.L., Neuhouser M.L., Gerner E.W., Meyskens F.L.: Developing of a polyamine database for assessing dietary intake. J Am Diet Assoc 2007, $107,1024-1027$ 